\title{
Horse Shampoo for Human Hair?
}

\author{
Anca Chiriac ${ }^{1,2,3}$, Mihai Mares ${ }^{4}$, Cristian Podoleanu5, Cosmin Moldovan' ${ }^{6}$, Simona Stolnicu ${ }^{7}$ \\ 1 Department of Dermato-Physiology, Apollonia University, lasi, Romania \\ 2 Department of Dermatology, Nicolina Medical Center, Iași, Romania \\ 3 "Petru Poni" Research Institute of Macromolecular Chemistry, Romanian Academy of Science, Iași, Romania \\ 4 "Ion Ionescu de la Brad" University of Agricultural Sciences and Veterinary Medicine, Iași, Romania \\ 5 Department of Cardiology, University of Medicine and Pharmacy, Tîrgu Mureș, Romania \\ 6 Department of Histology, University of Medicine and Pharmacy, Tîrgu Mureș, Romania \\ 7 Department of Pathology, University of Medicine and Pharmacy, Tîrgu Mureș, Romania
}

\section{CORRESPONDENCE}

\section{Cristian Podoleanu}

Str. Gheorghe Marinescu nr. 1 540139 Tîrgu Mureș, Romania

Tel: +40 265215133

E-mail: podoleanu@me.com

\section{ARTICLE HISTORY}

Received: 13 November, 2016

Accepted: 18 November, 2016
Anca Chiriac • Str. Muzicii nr. 2, 700399 lași, Romania. Tel: +40232210310

Mihai Mares • Al. Mihail Sadoveanu nr. 3, 700490 lași, Romania. Tel: +40 232213069

Cosmin Moldovan • Str. Gheorghe Marinescu nr. 38 540139 Tîrgu Mures, Romania. Tel: +40 265215551

Simona Stolnicu • Str. Gheorghe Marinescu nr. 38 540139 Tîrgu Mures, Romania. Tel: +40 265215551

\section{ABSTRACT}

Introduction: Lately, a new idea has caught the attention of young people of both genders, being debated in consultation rooms, during classes, and especially on social media: is using horse shampoo for human hair wrong or not? Material and methods: A simple questionnaire about horse shampoo and its use in humans was addressed to 85 students. Results: Thirtyeight responders were aware of its existence, 27 have tried it and 3 were still using it as a weekly shampoo. All positive responders were young women who declared being completely satisfied by horse shampoo and none of them have reported side effects. Conclusion: Although it has good reviews, horse shampoo is not available in human pharmacies. As dermatologists, we are still looking for an answer.

Keywords: horse shampoo, human hair, hair aesthetics

\section{INTRODUCTION}

The word "shampoo" originates from the Hindi word "champoo", which means cleaning the hair and scalp through massage. ${ }^{1}$ Hair shampoo, as it is nowadays known and used worldwide, contains synthetic surfactants and replaced soap in the 1930 s. $^{2}$

The ideal shampoo is designed to render the hair clean, soft, shiny and beautiful, according to modern demands. Its composition is important and is based on modern technology. Shampoo contains detergents, conditioning agents, additives, preservatives, foaming agents, thickeners and opacifiers, sequestering agents, $\mathrm{pH}$ adjusters, and special ingredients.

Lately, a new idea has lately caught the attention of young people of both genders, being debated in consultation rooms, during classes, and especially on social media: is using horse shampoo for human hair wrong or not? 


\section{MATERIAL AND METHODS}

A simple questionnaire with "yes" and "no" answers was addressed to 85 students from the fifth year of Medical School, in order to gather data about horse shampoo and its use in humans.

\section{RESULTS}

Out of the 85 students ( 43 women, $50.58 \%$ ), 38 were aware of the existence of horse shampoo, 27 have tried it and 3 were still using it as their weekly shampoo. All positive responders were young women who declared being completely satisfied by horse shampoo and none of them reported side effects.

\section{DISCUSSION}

There are no reports regarding short- or long-term use of horse shampoo by humans in PubMed and other medical resources. Nevertheless, by speaking directly to students and searching the Internet, one can find hundreds of declarations/statements about the positive effects of horse shampoo: "Horse shampoo makes the hair clean, good looking, feel soft, become thicker after use and it even helps hair growth"; "Horse shampoo is free of chemical substances, contains only natural ingredients, and thus it is natural"; or "No side effects have been described, and its lifetime use is safe and recommended".

By analysing in detail the product label of one of these shampoos, one can see the composition: Arctium lappa - radix, Betula pendula - folium, Equisetum arvense folium, Juglans regia - folium, Matricaria chamomilla flos, Salvia officinalis - folium, Urtica dioica - radix et folium, all of these being herb extracts. It also contains sodium lauryl sulphate, cocoamidopropil-betain, coc- odiethanolamid, substances described as antiseptics and detergents. It is indicated for equine use in regular applications. Nothing is mentioned about its use in humans, except to avoid direct contact with the eyes and genital areas, and a warning about its toxicity upon accidental ingestion. Sodium lauryl sulphate is an anionic detergent, commonly used on human hair, especially in oily conditions, due to its primary effect of efficient sebum removal. Cocodiethanolamide is a foaming agent with no cleaning properties that induces gas bubble formation in the water, improving the spread of the shampoo over the entire scalp. A high quantity of sebum inhibits the foaming action, and a second shampooing is necessary when better results are required. ${ }^{3}$

\section{RECOMMENDATIONS}

Although horse shampoo is designed for the equestrian market, one can find it only in the "Health and Personal Care" section, accompanied by numerous good reviews and recommendations. It does not exist in human pharmacies, but more diverse product types are available on the veterinarian market. As dermatologists, we are still looking for an answer.

\section{CONFLICTS OF INTEREST}

None declared.

\section{REFERENCES}

1. Campion MJ. Hobson-Jobson: The words English owes to India. Available online from http://www.bbc.com/news/magazine-18796493

2. Halligudi N, AL Khudori MS. Evaluation of cosmetic properties of different brands of shampoos from multinational brands in Oman. Journal of Drug Discovery and Therapeutics. 2013;1:91-96.

3. Draelos ZD. Essentials of hair care often neglected: Hair cleansing. Int J Trichology. 2010;2:24-29. 